\title{
Lesson of the month 2: An unusual adverse reaction associated with pramipexole
}

\author{
Authors: Yasmina Tashkent ${ }^{\mathrm{A}}$ and Vinod Aiyappan ${ }^{\mathrm{B}, \mathrm{C}}$
}

Dopamine agonists such as pramipexole are commonly used in the treatment of restless legs syndrome (RLS) as well as Parkinson's disease. Pramipexole's common side effects are well documented; however, adverse skin reactions are less well known. In this case, a 45-year-old male farmer presented with excessive daytime tiredness and reported a history suggestive of RLS. He was initiated on pramipexole but developed a maculopapular erythematous rash in sun-exposed areas 8 days after its commencement. The skin rash resolved following pramipexole's cessation and it is thought the patient experienced a drug-induced photosensitivity reaction to pramipexole. This case highlights the potential for photosensitivity reactions to pramipexole, which is especially significant in countries like Australia where UV solar radiation is especially high.

KEYWORDS: Pramipexole, adverse reaction, skin

\section{Presentation}

A 45-year-old male farmer presented with excessive daytime tiredness and reported a history suggestive of restless legs syndrome (RLS). He was otherwise fit and well with no significant past medical history, no history of allergies and was not on any medications. Further investigation revealed a normal biochemical profile and iron stores. A sleep study confirmed periodic limb movements in sleep associated with sleep fragmentation (Fig 1). He was initiated on pramipexole (Sifrol) $0.125 \mathrm{mg}$ nightly and had significant symptomatic improvement immediately after initiation of therapy. On the 8th day after initiation of treatment, the patient developed a maculopapular erythematous rash (Fig 2) in sun-exposed areas, while working outdoors on a sunny day. There were no symptoms of angioedema nor cardiorespiratory compromise. The patient's wife took photos of the rash on her mobile phone (Fig 2). His GP stopped the pramipexole and started him on a carbidopa-levodopa combination (Kinson 25/100 mg). The skin rash resolved and the patient did not develop an adverse reaction to the carbidopa-levodopa.

Authors: ${ }^{A}$ basic physician trainee, Flinders Medical Centre, Adelaide, Australia; ${ }^{\mathrm{B}}$ respiratory and sleep physician, Flinders Medical Centre, Adelaide, Australia; Clecturer in respiratory medicine, Flinders University, Adelaide, Australia

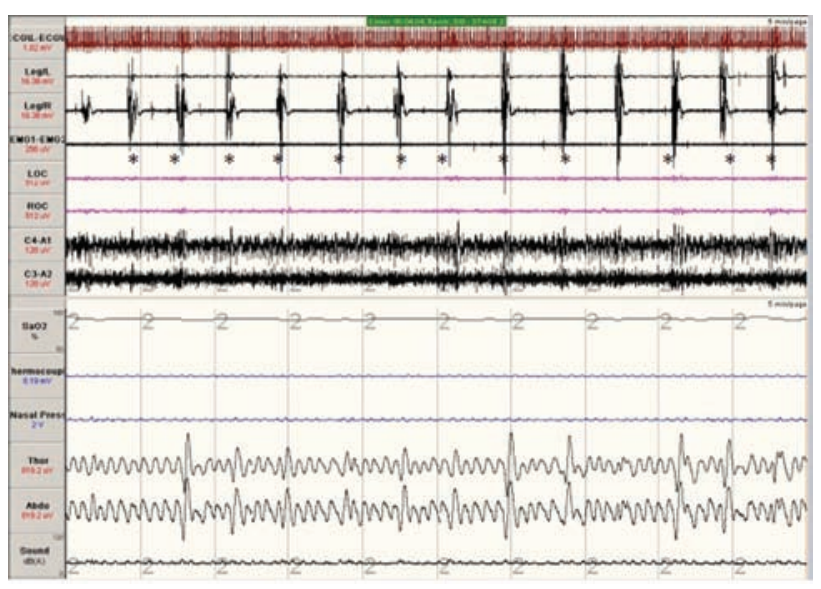

Fig 1. Polysomnography study revealing periodic limb movement disorder. (*Periodic limb movements.)

\section{Discussion}

Dopamine agonists, including pramipexole, a non-ergot, secondgeneration dopamine agonist, ${ }^{1}$ are recommended as first-line in the treatment of RLS. ${ }^{2}$ Pramipexole is also commonly used in the treatment of Parkinson's disease. Common side effects include insomnia, nausea, constipation, hallucinations, asthenia, sedation, somnolence, orthostatic hypotension, urinary frequency, dyskinesia and extrapyramidal side effects. ${ }^{3}$ In this case, it is thought the patient experienced a drug-induced photosensitivity reaction to pramipexole.

Photosensitivity reactions associated with exogenous agents are divided into photoallergy, phototoxicity and the induction/ exacerbation of systemic illness where photosensitivity is a major clinical finding (eg pellagra, lupus erythematosus and porphyria cutanea tarda). ${ }^{4}$ Photoallergic and phototoxic reactions can be difficult to distinguish but can be differentiated by certain features (Table 1). Photoallergy is thought to be a special type of a cell-mediated hypersensitivity reaction in which the drug is converted into an active compound by UV radiation, creating a photoantigen, which then triggers an immune response. This is in contrast to phototoxicity which occurs when light of a specific wavelength penetrates the skin and is absorbed by the drug or active drug metabolite that has reached the skin's cells, exciting electrons in the drug and producing unstable singlet/triplet 
Fig 2. Maculopapular confluent erythematous eruption involving the anterior chest wall (a) and left auricle (b).

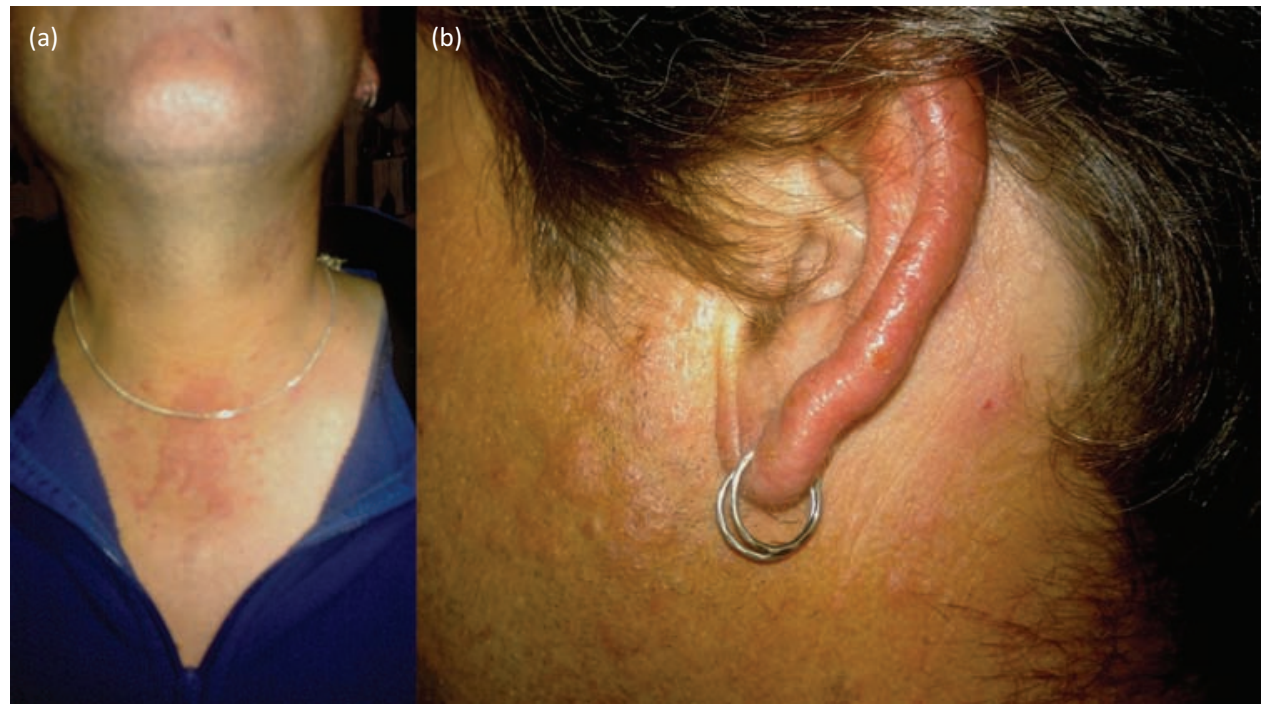

states. The damage to organelles and macromolecules and the inflammatory mediators produced by the energy transferred from the unstable molecules returning to ground state subsequently causes cell damage.

To date, only one other case of a phototoxic reaction from pramipexole has been reported in the literature. ${ }^{5}$ Although rare, photosensitivity reactions to pramipexole should be discussed with patients being initiated on this drug, especially in countries like Australia where solar UV radiation is $13 \%$ greater in the Southern

\begin{tabular}{|c|c|c|}
\hline & Photoallergy & Phototoxicity \\
\hline $\begin{array}{l}\text { Dosage of drug } \\
\text { required }\end{array}$ & Small & Large \\
\hline Onset & $>24$ hours & Minutes - hours \\
\hline Clinical features & $\begin{array}{l}\text { Dermatitis (acute, } \\
\text { subacute or chronic) } \\
\text { on exposed skin but } \\
\text { may also spread to } \\
\text { unexposed areas }\end{array}$ & $\begin{array}{l}\text { Exaggerated } \\
\text { sunburn only on } \\
\text { exposed skin }\end{array}$ \\
\hline $\begin{array}{l}\text { Persistent light } \\
\text { reaction }\end{array}$ & Yes & No \\
\hline \multirow[t]{3}{*}{ Histopathology } & Epidermal spongiosis & $\begin{array}{l}\text { Degeneration of } \\
\text { epidermal cells }\end{array}$ \\
\hline & $\begin{array}{l}\text { Dermal mononuclear } \\
\text { cell infiltrate }\end{array}$ & $\begin{array}{l}\text { Dermal vasodilation } \\
\text { and oedema }\end{array}$ \\
\hline & $\begin{array}{l}\text { Exocytosis of } \\
\text { mononuclear cells }\end{array}$ & $\begin{array}{l}\text { Sparse mononuclear } \\
\text { infiltrate }\end{array}$ \\
\hline
\end{tabular}

Hemisphere compared to corresponding sites in the Northern Hemisphere. ${ }^{6}$.

\section{Consent}

Consent was obtained from the patient to publish the clinical details and images in this article.

\section{References}

1 Deleu D, Northway MG, Hanssens Y. Clinical pharmacokinetic and pharmacodynamic properties of drugs used in the treatment of Parkinson's disease. Clin Pharmacokinet 2002;41:261-309.

2 Scholz H, Trenkwalder C, Kohnen R et al. Dopamine agonists for the treatment of restless legs syndrome. Cochrane Database Syst Rev 2011;3:CD006009.

3 Dooley M, Markham A. Pramipexole. A review of its use in the management of early and advanced Parkinson's disease. Drugs Aging 1998;12:495-514.

4 Gould JW, Mercurio MG, Elmets CA. Cutaneous photosensitivity diseases induced by exogenous agents. J Am Acad Dermatol 1995:33:551-73.

5 ElAhmed HH. Phototoxic rash during therapy with pramipexole in a patient with restless legs syndrome. Sultan Qaboos Univ Med J 2013;13:190-1.

6 McKenzie RL. Application of a simple model to calculate latitudinal and hemispheric differences in ultraviolet radiation. Weather Clim 1991:11:3-14.

Address for correspondence: Dr Yasmina Tashkent, Flinders Medical Centre, Division of Medicine, Flinders Drive, Bedford Park, South Australia 5042, Australia.

Email: Yasmina.Tashkent@sa.gov.au 